Supporting Information

\title{
Role of Bicarbonate Ions in Aqueous Solution as \\ a Carbon Source for Photocatalytic Conversion of $\mathrm{CO}_{2}$ into $\mathrm{CO}$
}

Rui Pang, ${ }^{\dagger}$ Kentaro Teramura, ${ }^{*},+,+$ Hiroyuki Asakura, ${ }^{\dagger,+}$ Saburo Hosokawa, ${ }^{\dagger,+}$ Tsunehiro

Tanaka $^{*, \dot{t}, \dot{t}}$

${ }^{\dagger}$ Department of Molecular Engineering, Graduate School of Engineering, Kyoto University, Kyoto 615-8510, Japan.

Elements Strategy Initiative for Catalysts and Batteries, Kyoto University, Kyoto 6158510, Japan.

\section{Corresponding Author}

*E-mail: teramura@moleng.kyoto-u.ac.jp (K.T)

*E-mail: tanakat@moleng.kyoto-u.ac.jp (T.T) 


\section{Photocatalytic reactions in $\mathrm{NH}_{4} \mathrm{HCO}_{3}$ solution.}

The reduction and oxidation reactions for the photocatalytic conversion of $\mathrm{CO}_{2}$ in the $\mathrm{NH}_{4} \mathrm{HCO}_{3}$ solution are shown as follows:

Reduction of $\mathrm{CO}_{2}: \mathrm{CO}_{2}+2 \mathrm{H}^{+}+2 \mathrm{e}^{-} \rightarrow \mathrm{CO}+\mathrm{H}_{2} \mathrm{O}$

Reduction of proton: $2 \mathrm{H}^{+}+2 \mathrm{e}^{-} \rightarrow \mathrm{H}_{2}$

Oxidation of $\mathrm{NH}_{3}: 2 \mathrm{NH}_{3} \rightarrow \mathrm{N}_{2}+6 \mathrm{H}^{+}+6 \mathrm{e}^{-}$

Oxidation of $\mathrm{NH}_{4}^{+}: 2 \mathrm{NH}_{4}^{+} \rightarrow \mathrm{N}_{2}+8 \mathrm{H}^{+}+6 \mathrm{e}^{-}$

The formation of $\mathrm{H}_{2}$ and $\mathrm{CO}$ consumed 2 electrons, and in the oxidation of $\mathrm{NH}_{3}$ or $\mathrm{NH}^{4+}$ to $\mathrm{N}_{2}$, six electrons are used. Thus, the balance between consumed electrons and holes can be calculated from the formation rates of each gases, as shown below:

Consumed $\mathrm{e}^{-} / \mathrm{h}^{+}=\left(2 \boldsymbol{R}_{\mathrm{CO}}+2 \boldsymbol{R}_{\mathrm{H} 2}\right) /\left(4 \boldsymbol{R}_{\mathrm{O} 2}+6 \boldsymbol{R}_{\mathrm{N} 2}\right)$

Where $\boldsymbol{R}_{\mathrm{CO}}, \boldsymbol{R}_{\mathrm{H} 2}, \boldsymbol{R}_{\mathrm{O} 2}$, and $\boldsymbol{R}_{\mathrm{N} 2}$ represent the formation rates of $\mathrm{CO}, \mathrm{H}_{2}, \mathrm{O}_{2}$, and $\mathrm{N}_{2}$, respectively.

When the photocatalytic reaction proceeds stoichiometrically, the ratio of electrons and holes should be equal to 1 . 


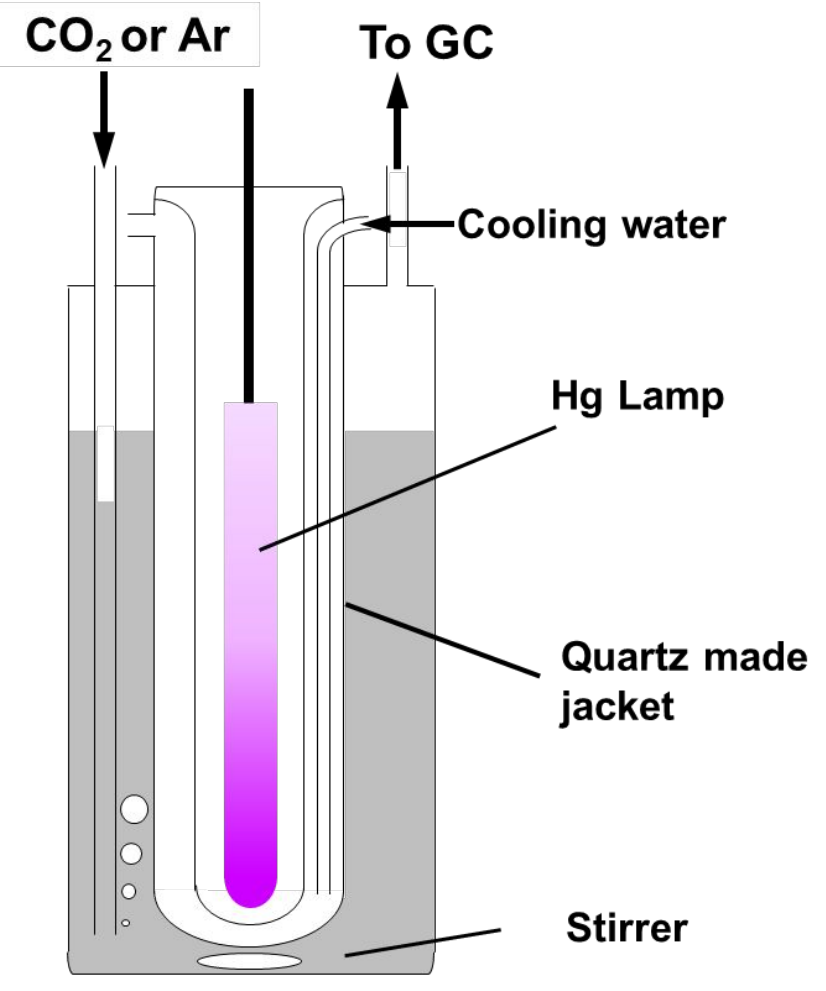

Figure. S1 Reactor set-up for the photocatalytic conversion of $\mathrm{CO}_{2}$. 

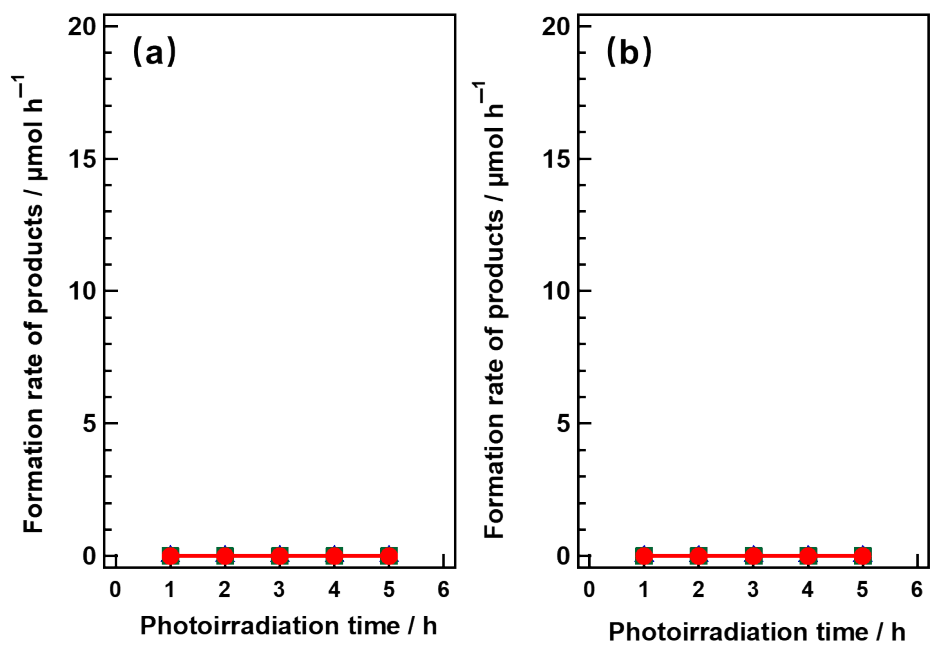

Figure S2. Formation rates of $\mathrm{H}_{2}$ (blue triangle), $\mathrm{O}_{2}$ (green square), and $\mathrm{CO}$ (red circle) for the photocatalytic conversion of $\mathrm{CO}_{2}$ in an $\mathrm{NaHCO}_{3}$ aqueous solution over $\mathrm{Ag} / \mathrm{SrNb}_{2} \mathrm{O}_{6}$ with the bubbling of $\mathrm{Ar}$ gas. (a) dark condition; (b) no photocatalyst. Photocatalyst: $1.0 \mathrm{wt} \% \mathrm{Ag} / \mathrm{SrNb}_{2} \mathrm{O}_{6}(0.5 \mathrm{~g})$, reaction solution volume: $\mathrm{H}_{2} \mathrm{O}(1.0 \mathrm{~L}), \mathrm{Ar}$

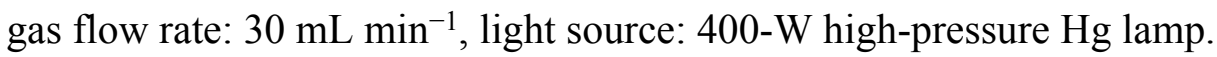




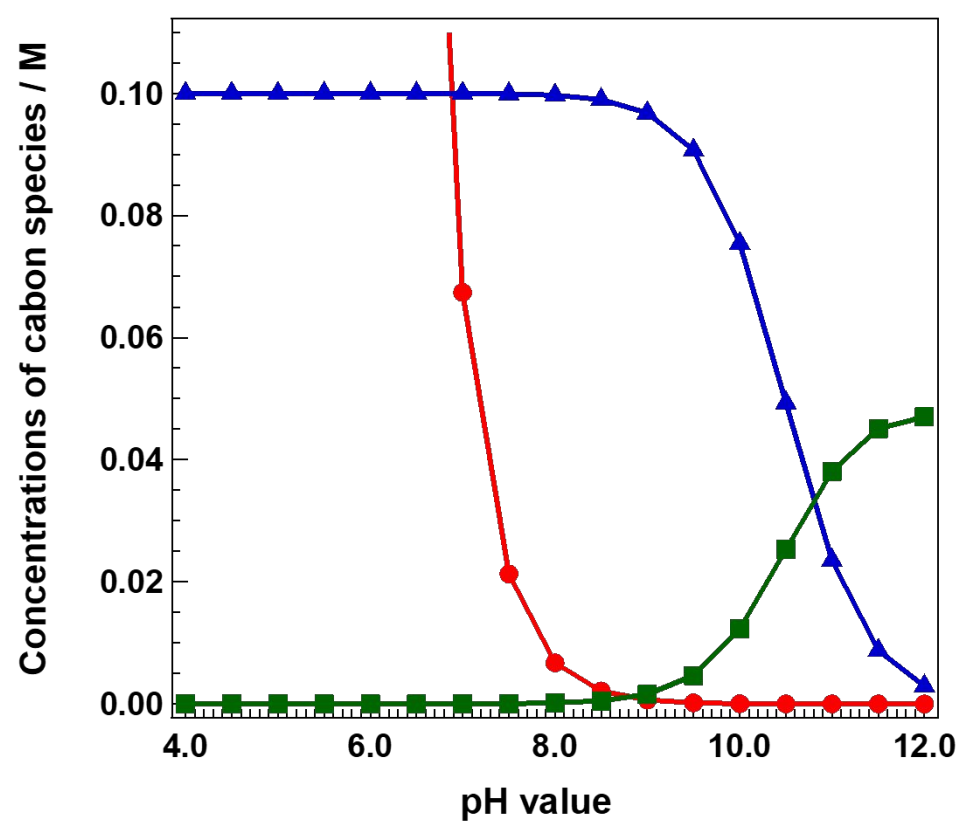

Figure S3. Calculated concentrations of $\mathrm{CO}_{2}$ (aq) (circle), $\mathrm{HCO}_{3}{ }^{-}$(triangle), and $\mathrm{CO}_{3}{ }^{2-}$ (square) in $0.10 \mathrm{M}$ aqueous solution of $\mathrm{NaHCO}_{3}$ at $303 \mathrm{~K}$ under $101.325 \mathrm{kPa}$ of $\mathrm{CO}_{2}$. 

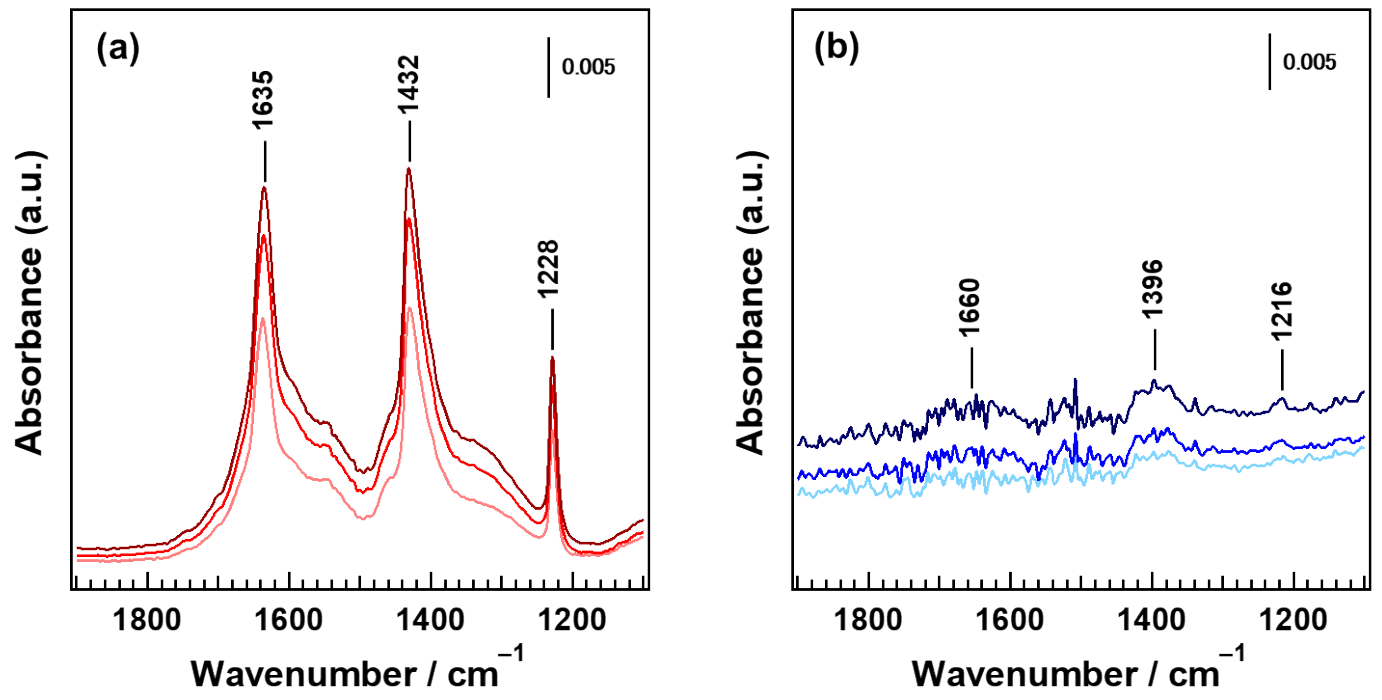

Figure S4. FTIR spectra for the $\mathrm{CO}_{2}$-adsorbed (a) $\mathrm{ZnGa}_{2} \mathrm{O}_{4} / \mathrm{Ga}_{2} \mathrm{O}_{3}$ and (b) $\mathrm{SrNb}_{2} \mathrm{O}_{6}$ samples after introducing the same amount of $\mathrm{CO}_{2}$ with a range of 3.0-25.0 Torr. 

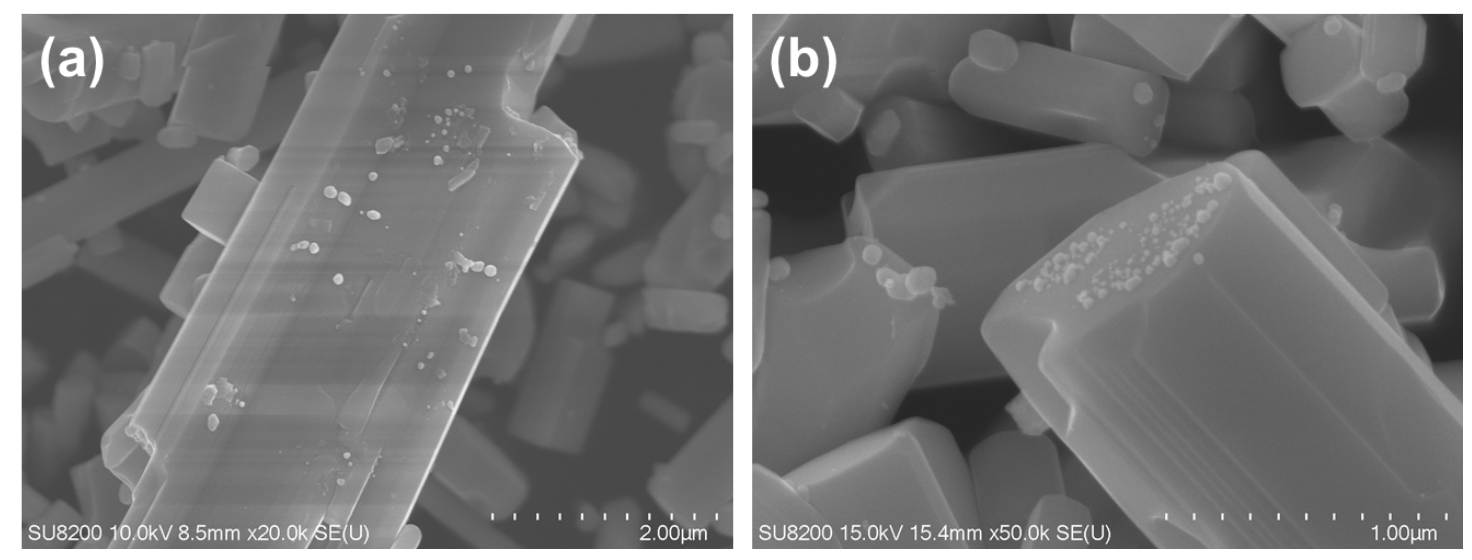

Figure S5. SEM images of $\mathrm{Ag} / \mathrm{SrNb}_{2} \mathrm{O}_{6}$ (a) before and (b) after photoirradiation for $5 \mathrm{~h}$. 


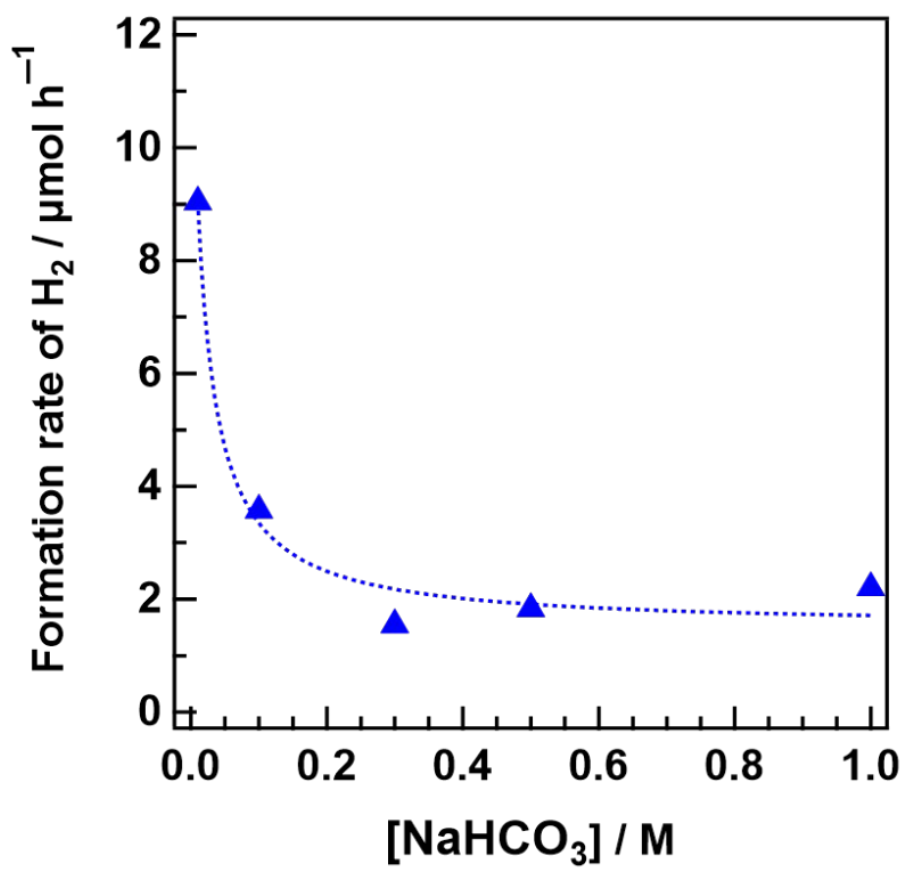

Figure S6. Formation rates of $\mathrm{H}_{2}$ at different concentrations of $\mathrm{NaHCO}_{3}$ for the photocatalytic conversion of $\mathrm{CO}_{2}$ after photoirradiation for $1 \mathrm{~h}$. Photocatalyst: $1.0 \mathrm{wt} \%$ $\mathrm{Ag} / \mathrm{SrNb}_{2} \mathrm{O}_{6}(0.5 \mathrm{~g})$, reaction solution volume: $\mathrm{H}_{2} \mathrm{O}(1.0 \mathrm{~L})$, Ar flow rate: $30 \mathrm{~mL} \mathrm{~min}{ }^{-1}$, light source: 400-W high-pressure Hg lamp. 


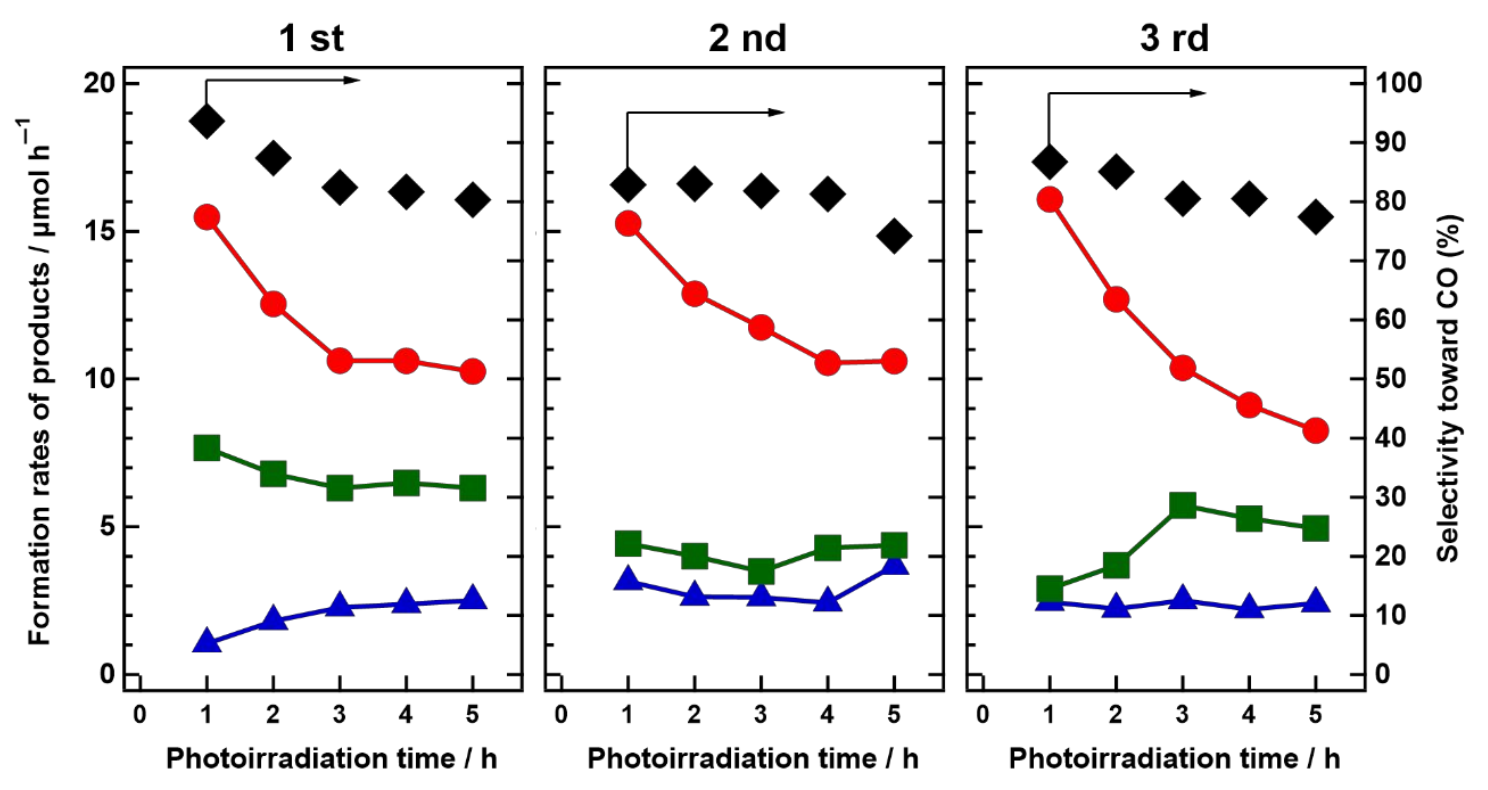

Figure S7. Formation rates of $\mathrm{H}_{2}$ (blue triangle), $\mathrm{O}_{2}$ (green square), $\mathrm{CO}$ (red circle) and selectivity toward $\mathrm{CO}$ evolution (black diamond) for the photocatalytic conversion of $\mathrm{CO}_{2}$ in $0.10 \mathrm{M} \mathrm{NaHCO}_{3}$ aqueous solution over $\mathrm{Ag} / \mathrm{SrNb}_{2} \mathrm{O}_{6}$ with the bubbling of $\mathrm{Ar}$ gas. After every five hours of photoirradiation, the $\mathrm{Ag} / \mathrm{SrNb}_{2} \mathrm{O}_{6}$ photocatalyst was washed and dried, and then repeated the photocatalytic reaction for twice. Photocatalyst: $1.0 \mathrm{wt} \%$ $\mathrm{Ag} / \mathrm{SrNb}_{2} \mathrm{O}_{6}(\sim 0.5 \mathrm{~g})$, reaction solution volume: $\mathrm{H}_{2} \mathrm{O}(1.0 \mathrm{~L})$, Ar gas flow rate: $30 \mathrm{~mL}$ $\min ^{-1}$, light source: 400-W high-pressure Hg lamp. 


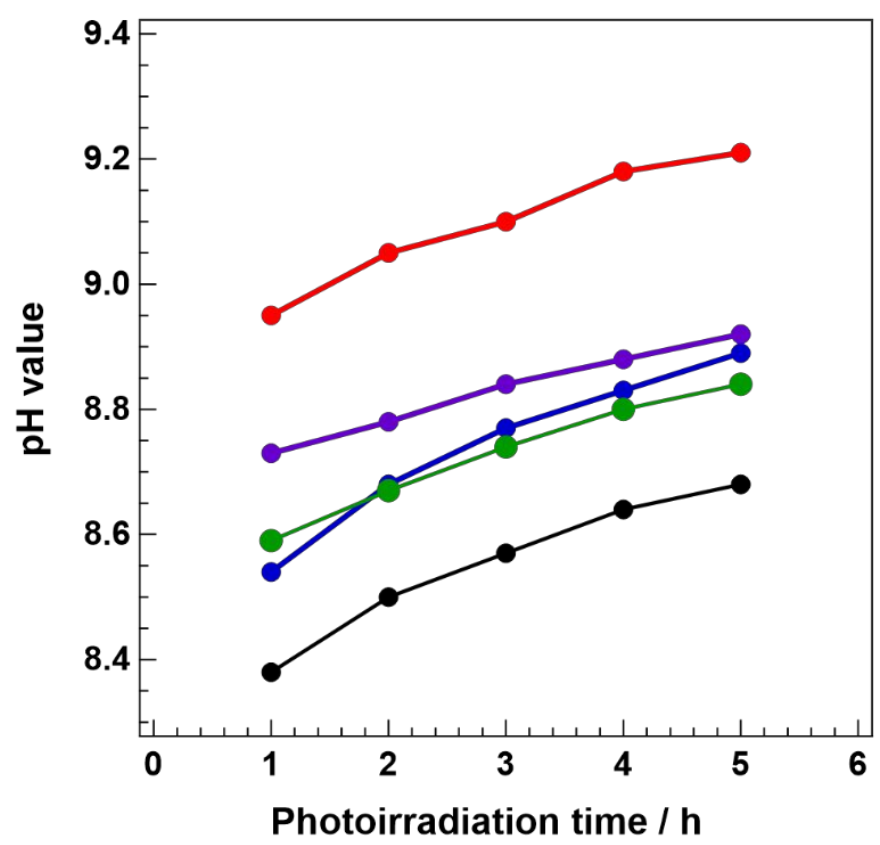

Figure S8. The $\mathrm{pH}$ of the reaction solutions during the photocatalytic conversion of $\mathrm{CO}_{2}$ for $5 \mathrm{~h}$ in different $\left[\mathrm{NaHCO}_{3}\right]$ solutions: $0.01 \mathrm{M}$ (red circle), $0.10 \mathrm{M}$ (purple circle), 0.30 $\mathrm{M}$ (blue circle), $0.50 \mathrm{M}$ (green circle), and 1.00 M (black circle). 

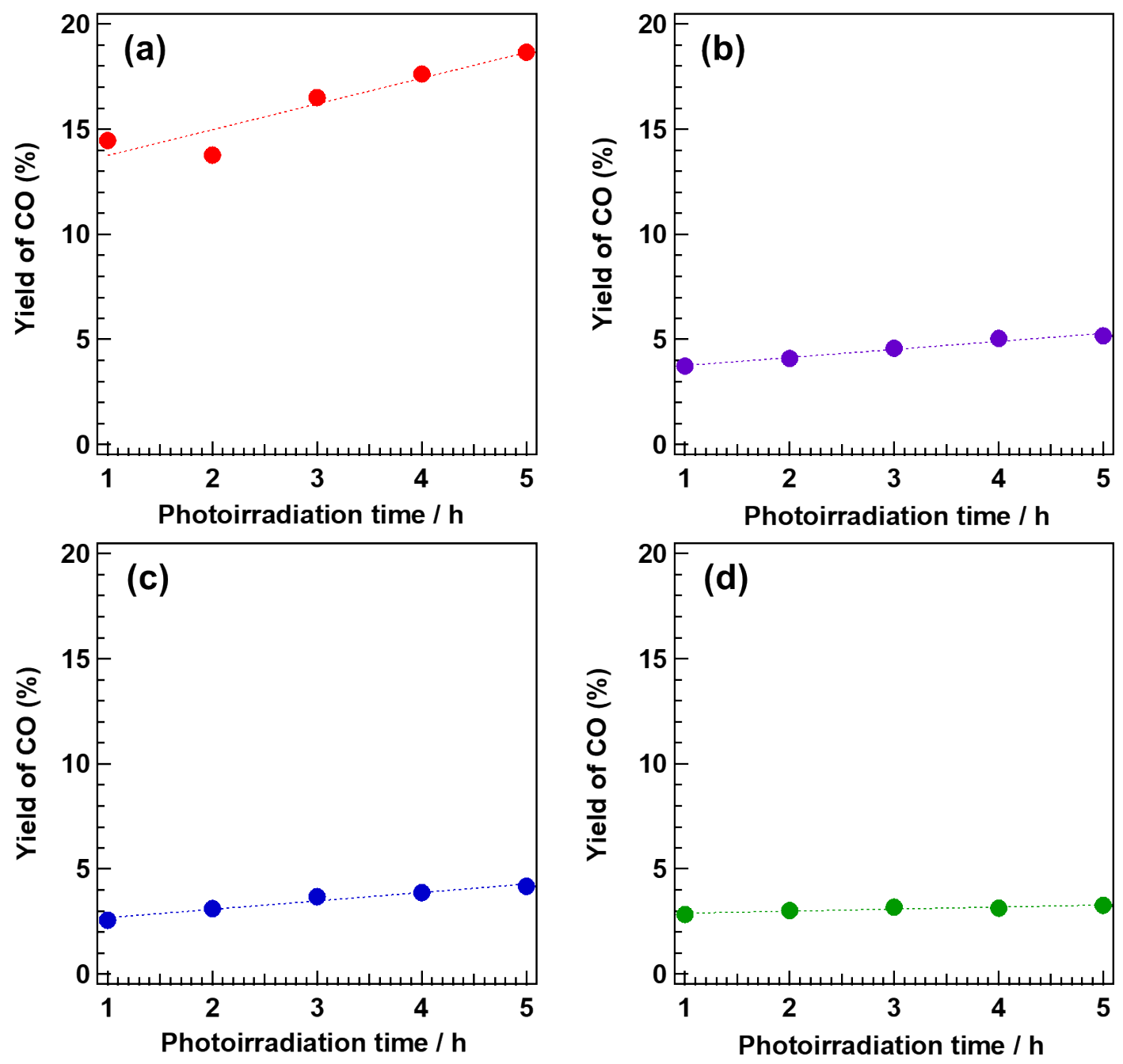

Figure S9. Yield of $\mathrm{CO}$ for the photocatalytic conversion of $\mathrm{CO}_{2}$ for $5 \mathrm{~h}$ in different $\left[\mathrm{NaHCO}_{3}\right]$ solutions: (a) $0.01 \mathrm{M}$, (b) $0.10 \mathrm{M}$, (c) $0.30 \mathrm{M}$, and (d) $0.50 \mathrm{M}$. 

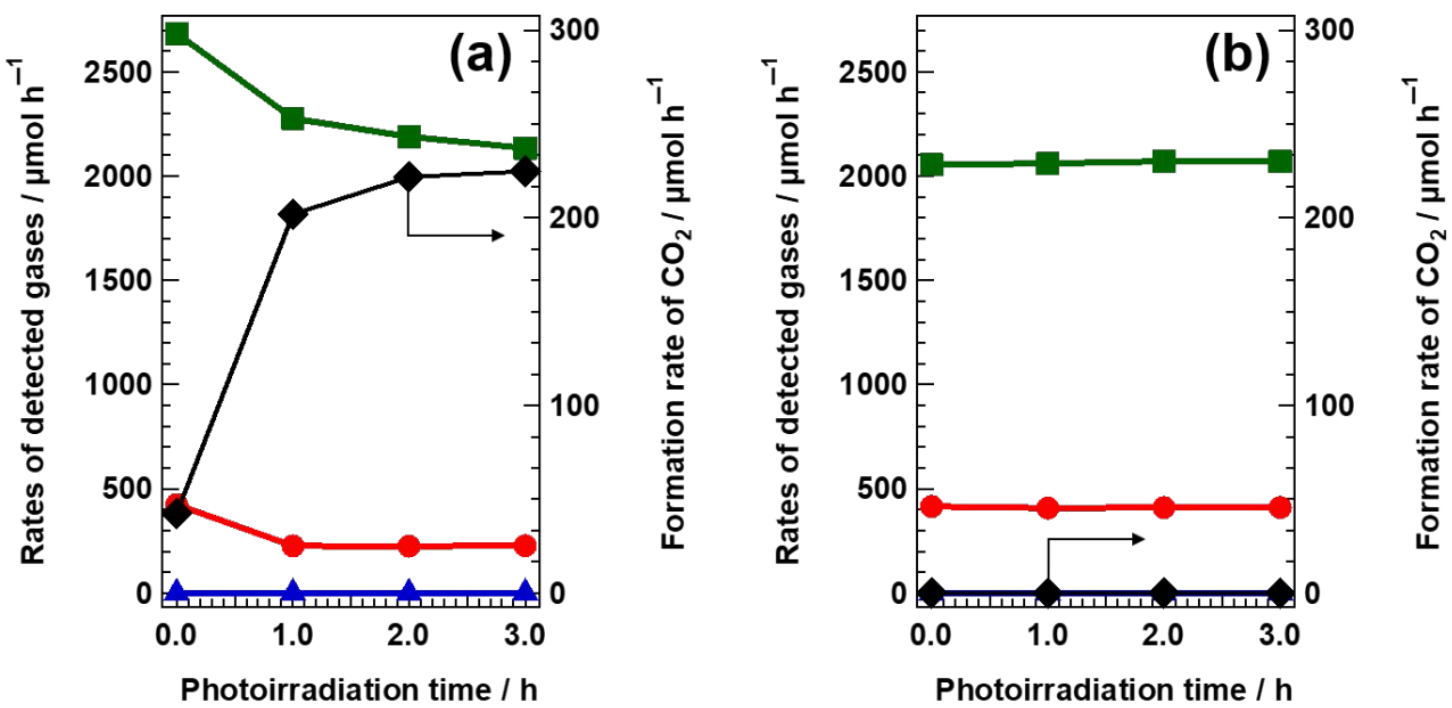

Figure S10. Rates of $\mathrm{H}_{2}$ (blue triangle), $\mathrm{O}_{2}$ (green square), $\mathrm{CO}$ (red circle) detected and the formation rate of $\mathrm{CO}_{2}$ (black diamond) of the backward reaction for the photocatalytic conversion of $\mathrm{CO}_{2}$ over $\mathrm{SrNb}_{2} \mathrm{O}_{6}$ in (a) $\mathrm{H}_{2} \mathrm{O}$ and (b) $\mathrm{NaHCO}_{3}$ solution. Photocatalyst powder: $0.5 \mathrm{~g}$, flowing rates of gases: $\mathrm{CO} / \mathrm{Ar}$ mixture gas (5.0\%): $2.7 \mathrm{~mL} \mathrm{~min}{ }^{-1}, \mathrm{O}_{2}: 1.0$

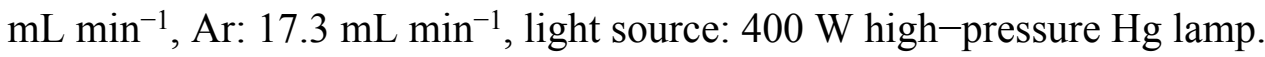

